\title{
A United States Population-Based Study on Clinical Outcomes Following Primary Carotid Endarterectomy: Who and When?
}

\author{
Shirali T. Patel ${ }^{1}$, Sachin V. Patil ${ }^{1}$, Ronald S. Chamberlain ${ }^{1,2,3}$ \\ ${ }^{1}$ Department of Surgery, Saint Barnabas Medical Center, Livingston, USA \\ ${ }^{2}$ Saint George’s University School of Medicine, St. George’s, Grenada \\ ${ }^{3}$ Department of Surgery, University of Medicine and Dentistry of New Jersey, Newark, USA \\ Email: RChamberlain@barnabashealth.org
}

Received September 17, 2012; revised October 18, 2012; accepted October 28, 2012

\begin{abstract}
Introduction: Carotid Endarterectomy (CEA) is widely recognized as effective in significantly reducing the risk of recurrent stroke emanating from extracranial carotid atherosclerosis and approximately 140,000 carotid endarterectomies are performed annually in the United States (US). As such, data are scarce on the prevalence and clinical outcomes of CEA across different age groups. This study aimed to determine and analyze the prevalence, demographic and clinical outcomes of CEA across six decades of life. Methods: Data on 40,276,240 patients were abstracted from discharge data obtained from the Nationwide Inpatient Sample (NIS) database, a part of the Healthcare Cost and Utilization Project (HCUP) of the Agency for Healthcare Research and Quality (2004-2008). Demographic and clinical characteristics of patients undergoing CEA as the primary procedure were abstracted including age, gender, elective or non-elective admission, comorbidities, Length of Stay (LOS), secondary procedures, NIS severity of illness and risk of mortality class, complications and mortality. CEA outcomes were compared across six decades of life starting at age 41. Categorical variables were compared using the Chi-square test, and the Student's $t$-test was used to compare continuous variables. Results: 118,947 patients who underwent CEA as their primary procedure were identified. Caucasians accounted for $67.1 \%$ of the population. The overall mean age was $71.2 \pm 9.5$ years, with a Male: Female ratio of 1.3:1. Nineteen percent of patients had non-elective admission, with the highest percentage (29.5\%) in those $>91$ years old. Over three percent of patients had a prior stroke. The overall number of CEA performed peaked in the 8th decade of life (38.4\%). The most common co-morbidities were hypertension, diabetes mellitus, and chronic pulmonary disease. Mean LOS was 3.3 days. Forty-two percent of all cases were performed in a teaching hospital, with the percentage increasing with advancing age. The overall mortality and stroke rates were $0.4 \%$ and $0.9 \%$, respectively, and these rates were highest in the oldest patients ( $>91$ years). The overall myocardial infarction rate was $0.8 \%$ which was highest incidence in the 7 th and 9th decades (1.1\%). On multivariate analysis, age >80 years (Odds Ratio (OR), 2.9; 95\% Confidence Interval (CI), 1.1 - 8.0), Non-white race (OR, 1.7; CI, 1.1 - 2.7), Charlson co-morbidity index score of 1 - 5 (OR, 1.7; CI, 1.3 - 2.4), carotid artery stenosis with stroke at presentation (OR, 1.7; CI, 1.1 - 2.5), Congestive Heart Failure (CHF) (OR, 3.7; CI, 2.8 - 4.8) and renal failure (OR, 2.2; CI, 1.6 - 3.1) were independent risk factors associated with increased CEA mortality. Conclusions: The percent of patients over 80 years is the fastest-growing segment of the US population, and CEA is an increasingly commonly procedure in elderly patients with a low mortality rate across all age groups. On a population level age $>80$, non-Caucasian race, the presence of specific co-morbidities (i.e., Stoke at presentation, congestive heart failure, renal failure), and a high Charlson co-morbidity index score are independent predictors of an increased CEA related mortality.
\end{abstract}

Keywords: Age Based Differences; Carotid Endarterectomy; Mortality

\section{Introduction}

Carotid Endarterectomy (CEA) is widely recognized as the most effective treatment for stroke prevention secondary to carotid artery stenosis, and approximately 140, 000 carotid endarterectomies are performed annually in the United States (US) [1]. The risk of the Cerebrovascu- lar Accident (CVA) is closely linked to aging, and with each decade after age 55 , the incidence of stroke doubles in both men and women [2,3]. CVA is currently the second most common cause of death in patients over 85 years [2]. It has been predicted that the proportion of the US population over 80 years old is expected to double 
in the next four decades going from 5\% (1990) to $10 \%$ (2030) [2]. In addition, Americans 65 to 79 years who constituted $9.3 \%$ of the population in 2000 is projected to increase to $12.5 \%$ by 2050 and $12.9 \%$ by 2070 [4]. Given current life table analysis that predicts that patients who survive to the age of 80 - 85 years old will live another eight years on average, the number of elderly patients (>80 years) who will require CEA will increase dramatically in the near future [5]. Despite these facts, little is known about the clinical outcomes of the elderly patients following most surgical interventions since they are largely excluded from clinical trials given their presumed "high risk" status. To date, only scant data exists on the outcomes of octogenarians following CEA, and all those published, suggest that the elderly have higher complications, Length of Stay (LOS), and mortality compared to younger patients [6-10]. That said, small sample size, the lack of study design uniformity, and confounding variables among existing reports on CEA outcomes across different age groups, make the existing information of little value, to risk stratify specific patients, and to make informed surgical decisions. This study sought to use a large population-based database to evaluate prevalence and clinical outcomes of CEA across six decades of life and to determine independent demographic and clinical factors, which influenced CEA related in-hospital morbidity and mortality.

\section{Materials and Methods}

Discharge data on 40,276,240 patients from the Nationwide Inpatient Sample (NIS) data, a part of the Healthcare Cost and Utilization Project (HCUP) of the Agency for Healthcare Research and Quality (AHRQ) database, was analyzed over a five-year period (2004-2008). Carotid Endarterectomy (CEA), as a primary procedure, was identified using ICD 9 code 38.12. Demographic and clinical characteristics of patients undergoing CEA as the primary procedure were abstracted including age, gender, elective or non-elective nature of admission, co-morbidities, Length of Stay (LOS), LOS before surgery, complications and mortality. Corrected LOS was calculated by subtracting the pre-procedural LOS from overall LOS. Patients with asymptomatic carotid artery stenosis at admission were identified using ICD-9 CM code 433.10, and patients with stroke due to carotid artery stenosis at admission were identified using ICD-9 CM code 433.11. The ICD-9-CM codes used to identify complication rates were 997.02 for post-operative stroke, 951.3 951.9 for cranial nerve injuries, 998.11 for post-operative hemorrhage, 998.12 for post-operative hematoma, and 410.00 - 410.02, 410.10 - 410.12, 410.20 - 410.22, 410.30410.32, 410.40 - 410.42, 410.50 - 410.52, 410.60 - 410.62, 410.70 - 410.72, 410.80 - 410.82, 410.90 - 410.92 for
Myocardial Infarction (MI). Six age groups, in increments of 10 years, were analyzed starting at age 41 . Charlson co-morbidity index scores were calculated for each age group using available co-morbidity information. The Charlson co-morbidity index score was calculated by using the co-morbidity information provided in the NIS database, by applying appropriate scores as mentioned (Table 1) to arrive at the final score. The information on myocardial infarction, dementia and leukemia was abstracted using ICD 9 codes. In the NIS database there is no differentiation between mild liver disease and moderate to sever liver disease, all the patients with co-morbidity information of chronic liver disease were grouped under mild liver disease. Although patients $>50$ years should receive a score of at least 1 , patients without any

Table 1. Calculation of charlson's co-morbidity index score using variables provided in national Inpatient database.

\begin{tabular}{|c|c|}
\hline Co-morbidity & Charlson Score \\
\hline Myocardial infarction $^{\dagger}$ & 1 \\
\hline Congestive heart failure & 1 \\
\hline Peripheral vascular disease & 1 \\
\hline Cerebrovascular disease & 1 \\
\hline Dementia $^{\dagger}$ & 1 \\
\hline COPD & 1 \\
\hline Connective tissue disorder & 1 \\
\hline Peptic ulcer disease & 1 \\
\hline Mild liver disease $e^{\ddagger}$ & 1 \\
\hline Diabetes without complications & 1 \\
\hline Hemiplegia & 2 \\
\hline Moderate to sever renal disease & 2 \\
\hline Diabetes with organ damage & 2 \\
\hline Solid tumor & 2 \\
\hline Leukemia $^{\dagger}$ & 2 \\
\hline Lymphoma & 2 \\
\hline Moderate to sever liver disease $\mathrm{e}^{\ddagger}$ & 5 \\
\hline Metastatic solid tumor & 6 \\
\hline AIDS & 6 \\
\hline \multicolumn{2}{|l|}{ Age groups } \\
\hline 41 - 50 years & 0 \\
\hline $51-60$ years & 1 \\
\hline $61-70$ years & 2 \\
\hline 71 - 80 years & 3 \\
\hline 81 - 90 years & 4 \\
\hline$>90$ years & 5 \\
\hline
\end{tabular}

${ }^{\dagger}$ Information abstracted using ICD 9 codes; ${ }^{\ddagger}$ In the NIS database there is no differentiation between mild liver disease and moderate to severe liver disease. All the patients with a co-morbidity of chronic liver disease were grouped under mild liver disease. 
co-morbidities were not assigned any age-related charlson scores. We did not utilize the discharge weights (to estimate the national figures) in order to limit our calculations and results to actual patients. Similarly, as per NIS database reporting guidelines, values $<10$ were not shown in the results section.

\section{Statistical Analysis}

IBM $^{\circledR}$ SPSS 18 (SPSS Inc. Released 2009. PASW Statistics for Windows, Version 18.0. Chicago: SPSS Inc.) was used for all statistical calculations. Categorical variables were compared using the Chi-square test, and the Student's $t$-test was used to compare continuous variables. A value of $p<0.05$ was considered statistically significant. An analysis of variance (ANOVA) and Tukey's B post hoc tests were used to study the effect age on LOS. Univariate analysis was performed to study the effect of demographic and clinical variables on mortality. Risk factors associated with CEA related in-hospital mortality were entered into multivariate logistic regression analysis. Backward stepwise method was used to perform regression analysis. In backward stepwise logistic regression the analysis begins with a full or saturated model, and variables are eliminated from the model in an iterative process. The fit of the model is tested after the elimination of each variable to ensure that the model still adequately fit the data. When no more variables can be eliminated from the model, the analysis has been completed.

\section{Results}

\subsection{Demographic and Clinical Variables}

A total of $118,947(0.3 \%)$ patients aged $>40$ years that underwent a CEA as their primary procedure between 2004 and 2008 formed the study group (Table 2). The mean age \pm standard deviation of the overall population was $71.2 \pm 9.5$ years with a Male: Female ratio of 1.3:1. The highest numbers of cases (38.4\%) were performed in 8th decade of life. More male patients underwent CEA between the 6th and 9th decade, whereas nearly equal numbers of male and female patients underwent CEA in the 4th and 10th decades, $p<0.001$. The number of CEA performed increased with age across all racial/ethinic groups, and peaked in patients $>80$ years. The five specific racial/ethnic groups analyzed were Caucasian, AfricanAmerican (AA), Hispanic, Asian or Pacific-Islander and Native Americans. Among those patients in whom racial/ethnic demographics were available, $89.4 \%$ of all CEA cases were performed in Caucasians, with $87 \%$ of cases performed after age 60 and peaking between 71 and 80 years.

Non-elective/Emergent admissions accounted for 19.3\% of cases, and this percent peaked in those 41 - 50 years
(27\%), and the oldest patients ( $>91$ years, 29.5\%). Among patients for whom history of prior stroke was available, $86.9 \%$ of patients upon whom a CEA was performed had no history of stroke. Patients $>91$ years were most likely to have a history of stroke at admission (5.7\%).

\subsection{Co-Morbidities}

Hypertension (HTN) (78.1\%), uncomplicated Diabetes Mellitus (DM) (26.9\%), Chronic Pulmonary Disease (COPD) (21.4\%), peripheral vascular disease (PVD) (19.7\%), Congestive Heart Failure (CHF) (6.7\%), Renal Failure (RF) (5.2\%), diabetes with chronic complications (2.8\%), and liver disease $(0.5 \%)$ were the most common co-morbidities reported among the study group (Table 3). Younger patients had a higher incidence of chronic comorbidities such as DM, COPD, and PVD than the oldest patients, while older patients had a higher incidence of CHF and RF. Overall 58.7\% ( $=69841)$ of patients had a Charlson co-morbidity score between 1 and 5 , with the peak observed in the 7 th decade. Only $0.4 \%(\mathrm{~N}=520)$ of patients had a Charlson co-morbidity score of $>5$, with the highest incidence in the youngest population (41 - 50 years, $0.6 \%)$.

\subsection{Hospital Outcomes and Demographics}

Less than half of all CEAs were performed in facilities designating themselves as "teaching hospitals (42.4\%)", while $90.9 \%$ of all CEAs were performed in "urban" hospitals, as opposed to rural or community facilities (Table 4). These percentages were fairly consistent across all age groups. The mean Length of Stay (LOS) prior to CEA was $0.7 \pm 2$ days, and this increased with age starting from the 6th decade and peaking in the oldest group (>91 years, $1.4 \pm 2.8$ days). Mean LOS was $2.6 \pm 3.5$ days, and similarly increased with age peaking in the oldest age group ( $>91$ years, $3.9 \pm 4.2$ days). Overall LOS and corrected LOS were $2.6 \pm 3.5$ days and $2.0 \pm$ 2.5 days, respectively and similarly increased with age peaking in the oldest age group ( $>91$ years, $3.9 \pm 4.2$ days and $2.6 \pm 2.4$ days, respectively). LOS prior to CEA and total LOS were higher in the youngest age patients compared to those in the 6th through 9th decades, which is likely attributable to a high non-elective CEA admission rate (27\%). Tukey B post hoc test was used to study the effect of age on LOS. Patients between 6th and 8th decade had lowest LOS, compared to $>80$ years who had highest LOS whereas those in 5th decade had LOS lying somewhere in the middle, $p<0.01$ (Table 5)

Ninety percent of all CEA patients in the study group were discharged to home without a home-health aide at the end of hospitalization, this included $67.1 \%$ of those $>91$ years of age. Nearly six percent of the patients required a home-health aide for some assistance, which increased 
Table 2. Demographic and clinical profile of 118,947 patients undergoing Carotid Endarterectomy (CEA) as a primary procedure between 2004 and 2008.

\begin{tabular}{|c|c|c|c|c|c|c|c|}
\hline \multirow{2}{*}{$\begin{array}{c}\text { Demographic and clinical } \\
\text { variables }\end{array}$} & \multirow{2}{*}{ Overall } & \multicolumn{6}{|c|}{ Patients' age groups by decades } \\
\hline & & $\begin{array}{l}41-50 \\
\text { years }\end{array}$ & $\begin{array}{l}51-60 \\
\text { years }\end{array}$ & 61 - 70 years & 71 - 80 years & 81 - 90 years & $\begin{array}{c}>91 \\
\text { years }\end{array}$ \\
\hline $\mathrm{N}$ & 118,947 & 2420 & 14,270 & 36,067 & 45,663 & 19,910 & 617 \\
\hline Mean Age \pm SD & $71.2 \pm 9.5$ & $47.3 \pm 2.5$ & $56.5 \pm 2.7$ & $65.9 \pm 2.8$ & $75.3 \pm 2.8$ & $83.9 \pm 2.5$ & $92.5 \pm 1.7$ \\
\hline Male: Female ratio ${ }^{\dagger}$ & $1.3: 1$ & 1.1:1 & 1.4:1 & 1.4:1 & 1.4:1 & $1.2: 1$ & $1.0: 1$ \\
\hline \multicolumn{8}{|l|}{ Race, N (\%) ${ }^{\dagger}$} \\
\hline Caucasians & 79,836 (89.4) & 1488 (85.9) & $9128(87.6)$ & 23,882 (89.0) & $31,052(89.7)$ & $13,868(91.0)$ & 418 (92.9) \\
\hline African-American & $3185(3.6)$ & $98(5.7)$ & $495(4.8)$ & $1047(3.9)$ & $1121(3.2)$ & $412(2.7)$ & $12(2.7)$ \\
\hline Hispanic & $3426(3.8)$ & $80(4.6)$ & 384 (3.7) & $1058(3.9)$ & $1370(4.0)$ & $525(3.4)$ & $(-)$ \\
\hline Asian or Pacific Islander & $833(0.9)$ & $11(0.6)$ & $104(1.0)$ & $231(0.9)$ & $352(1.0)$ & $134(0.9)$ & $(-)$ \\
\hline Native American & $366(0.4)$ & $13(0.8)$ & $65(0.6)$ & $115(0.4)$ & $129(0.4)$ & $43(0.3)$ & $(-)$ \\
\hline Other & $1651(1.8)$ & $42(2.4)$ & $240(2.3)$ & 495 (1.8) & $606(1.7)$ & 259 (1.7) & $(-)$ \\
\hline Non-elective cases, $\mathrm{N}(\%)^{\dagger}$ & 22,912 (19.3) & $652(27)$ & 2969 (20.8) & $6523(18.1)$ & $8318(18.2)$ & $4268(21.5)$ & $182(29.5)$ \\
\hline \multicolumn{8}{|l|}{ Primary diagnosis, N (\%) } \\
\hline $\begin{array}{l}\text { Carotid artery occlusion } \\
\text { without stroke }\end{array}$ & 103,353 (86.9) & 1987 (82.1) & $\begin{array}{l}12,260 \\
(85.9)\end{array}$ & 31,457 (87.2) & 39,829 (87.2) & 17,294 (86.9) & $526(85.3)$ \\
\hline $\begin{array}{l}\text { Carotid artery occlusion with } \\
\text { stroke }^{\dagger}\end{array}$ & 3896 (3.3) & $181(7.5)$ & $575(4.0)$ & $1095(3.0)$ & $1303(2.9)$ & 707 (3.6) & $35(5.7)$ \\
\hline Mortality, N (\%) ${ }^{\dagger}$ & $438(0.4)$ & $(0.2)^{\ddagger}$ & $30(0.2)$ & $97(0.3)$ & $166(0.4)$ & $133(0.7)$ & $(1.1)^{\ddagger}$ \\
\hline $\begin{array}{c}\text { Combined stroke/mortality, } \mathrm{N} \\
(\%)^{\dagger}\end{array}$ & $1466(1.2)$ & $(0.2)^{\ddagger}$ & $162(1.1)$ & $404(1.1)$ & $526(1.2)$ & $326(1.6)$ & $16(2.6)$ \\
\hline
\end{tabular}

Abbreviation: N: number of patients; SD: standard deviation; (-): As per NIS database reporting guidelines values <10 are not shown in the table; ${ }^{\dagger} p$ value $<0.001$, significant for trend; ${ }^{\ddagger}$ As per NIS database reporting guidelines values $<10$ are not shown in the table.

Table 3. Co-morbidity profile of $\mathbf{1 1 8 , 9 4 7}$ patients undergoing Carotid Endarterectomy (CEA) as a primary procedure between 2004 and 2008.

\begin{tabular}{|c|c|c|c|c|c|c|c|}
\hline & \multirow[t]{2}{*}{ Overall } & \multicolumn{6}{|c|}{ Patients' age groups by decades } \\
\hline & & 41 - 50 years & 51 - 60 years & 61 - 70 years & 71 - 80 years & 81 - 90 years & $>91$ years \\
\hline \multicolumn{8}{|l|}{ Co-morbidities, $\mathrm{N}(\%)^{\dagger}$} \\
\hline Hypertension & $92,948(78.1)$ & 1715 (70.9) & $10,653(74.7)$ & $28,274(78.4)$ & 36,087 (79) & $15,766(79.2)$ & $453(73.4)$ \\
\hline Diabetes, uncomplicated & 31,961 (26.9) & $594(24.5)$ & $4007(28.1)$ & $10,588(29.4)$ & $12,450(27.3)$ & $4251(21.4)$ & $71(11.5)$ \\
\hline $\begin{array}{c}\text { Chronic pulmonary } \\
\text { disease }\end{array}$ & $25,488(21.4)$ & $417(17.2)$ & 2899 (20.3) & 8549 (23.7) & $9974(21.8)$ & $3574(18)$ & $75(12.2)$ \\
\hline $\begin{array}{c}\text { Peripheral vascular } \\
\text { disease }\end{array}$ & 23,460 (19.7) & $422(17.4)$ & 2750 (19.3) & 7502 (20.8) & 9041 (19.8) & 3658 (18.4) & $87(14.1)$ \\
\hline Congestive heart failure & $7938(6.7)$ & $71(2.9)$ & $591(4.1)$ & $1996(5.5)$ & $3308(7.2)$ & $1890(9.5)$ & $82(13.3)$ \\
\hline $\begin{array}{l}\text { Diabetes with chronic } \\
\text { complications }\end{array}$ & $3283(2.8)$ & $88(3.6)$ & $475(3.3)$ & $1102(3.1)$ & $1228(2.7)$ & $386(1.9)$ & $4(0.6)$ \\
\hline Renal failure & $6191(5.2)$ & $73(3.0)$ & $456(3.2)$ & $1637(4.5)$ & $2633(5.8)$ & $1345(6.8)$ & $47(7.6)$ \\
\hline \multicolumn{8}{|l|}{ Charlson co-morbidity score $^{\dagger}$} \\
\hline 0 & $48,586(40.8)$ & $1154(47.7)$ & $6097(42.7)$ & $13,899(38.5)$ & $18,241(39.9)$ & $8862(44.5)$ & $333(54.0)$ \\
\hline $1-5$ & $69,841(58.7)$ & $1252(51.7)$ & $8111(56.8)$ & $22,017(61.0)$ & $27,214(59.6)$ & $10,964(55.1)$ & $283(45.9)$ \\
\hline$>5$ & $520(0.4)$ & $14(0.6)$ & $62(0.4)$ & $152(0.4)$ & $208(0.5)$ & $83(0.4)$ & $(-)$ \\
\hline
\end{tabular}

Abbreviation: N: number of patients; (-): As per NIS database reporting guidelines values $<10$ are not shown in the table; ${ }^{\dagger} p$ value $<0.001$, significant for trend. 
Table 4. Hospital status, Discharge Data and Cost of Care Analysis for 118,947 patients undergoing Carotid Endarterectomy (CEA) as a primary procedure between 2004 and 2008, based on hospital status.

\begin{tabular}{|c|c|c|c|c|c|c|c|}
\hline \multirow{2}{*}{ Hospital status, $\mathrm{N}(\%)^{\dagger}$} & \multirow[t]{2}{*}{ Overall } & \multicolumn{6}{|c|}{ Patients' age groups by decades } \\
\hline & & 41 - 50 years & 51 - 60 years & $61-70$ years & 71 - 80 years & 81 - 90 years & $>91$ years \\
\hline Non-Teaching hospital & $68,642(57.7)$ & $1282(53.0)$ & $7737(54.2)$ & $20,600(57.1)$ & $26,703(58.5)$ & $11,937(60.0)$ & $383(62.1)$ \\
\hline Teaching hospital & $50,288(42.3)$ & $1138(47.0)$ & $6530(45.8)$ & $15,459(42.9)$ & $18,958(41.5)$ & $7969(40.0)$ & 234 (37.9) \\
\hline Non-urban hospital & $10,774(9.1)$ & 225 (9.3) & $1300(9.1)$ & $3267(9.1)$ & $4182(9.2)$ & $1735(8.7)$ & $65(10.5)$ \\
\hline Urban hospital & $108,156(90.9)$ & $2195(90.7)$ & 12,967 (90.9) & $32,792(90.9)$ & $41,479(90.8)$ & $18,171(91.3)$ & $552(89.5)$ \\
\hline $\begin{array}{l}\text { LOS before procedure, } \\
\text { days (mean } \pm \mathrm{SD})^{\dagger}\end{array}$ & $0.7 \pm 2.3$ & $1.0 \pm 2.7$ & $0.7 \pm 2.0$ & $0.6 \pm 1.8$ & $0.6 \pm 2.7$ & $0.8 \pm 2.2$ & $1.4 \pm 2.8$ \\
\hline $\begin{array}{l}\text { Length of stay, days } \\
\quad(\text { mean } \pm \text { SD })^{\dagger}\end{array}$ & $2.6 \pm 3.5$ & $2.8 \pm 3.9$ & $2.4 \pm 3.2$ & $2.4 \pm 3.3$ & $2.6 \pm 3.6$ & $3.1 \pm 4.0$ & $3.9 \pm 4.2$ \\
\hline $\begin{array}{l}\text { Corrected LOS } \\
(\text { mean } \pm \mathrm{SD})^{\dagger}\end{array}$ & $2.0 \pm 2.5$ & $1.8 \pm 2.5$ & $1.8 \pm 2.2$ & $1.8 \pm 2.3$ & $2.0 \pm 2.6$ & $2.3 \pm 2.8$ & $2.6 \pm 2.4$ \\
\hline \multicolumn{8}{|l|}{ Discharge status, $\mathrm{N}(\%)^{\dagger}$} \\
\hline Routine & $105,696(88.9)$ & 2264 (93.6) & $13,316(93.3)$ & $33,343(92.4)$ & $40,404(88.5)$ & $15,955(80.2)$ & $414(67.1)$ \\
\hline Home health care & $6893(5.8)$ & $75(3.1)$ & $508(3.6)$ & $1495(4.1)$ & $2846(6.2)$ & $1900(9.5)$ & $69(11.2)$ \\
\hline Nursing home & $5475(4.6)$ & $63(2.6)$ & $364(2.6)$ & $1000(2.8)$ & $2091(4.6)$ & $1834(9.2)$ & $123(19.9)$ \\
\hline Short term hospital & $337(0.3)$ & $(0.2)^{\ddagger}$ & $41(0.3)$ & $88(0.2)$ & $128(0.3)$ & $73(0.4)$ & $(0.5)^{\ddagger}$ \\
\hline Against medical advice & $89(0.1)$ & $(0.3)^{\ddagger}$ & $(0.1)^{\ddagger}$ & $39(0.1)$ & $22(0.05)$ & $(0.05)^{\ddagger}$ & $(0.2)^{\ddagger}$ \\
\hline Unknown & $12(0.01)$ & $2(0.08)$ & 0 & $(0.01)^{\ddagger}$ & $(0.01)^{\ddagger}$ & $(0.03)^{\ddagger}$ & 0 \\
\hline $\begin{array}{l}\text { Total hospital charges, } \\
\text { mean } \pm \mathrm{SD}^{\dagger}\end{array}$ & $\begin{array}{l}25969.37 \pm \\
26876.299\end{array}$ & $\begin{array}{l}27208.06 \pm \\
28298.407\end{array}$ & $\begin{array}{l}25155.46 \pm \\
24724.392\end{array}$ & $\begin{array}{l}25029.06 \pm \\
25814.679\end{array}$ & $\begin{array}{l}25868.07 \pm \\
27238.656\end{array}$ & $\begin{array}{l}28190.42 \pm \\
28923.412\end{array}$ & $\begin{array}{l}30586.85 \pm \\
29300.288\end{array}$ \\
\hline
\end{tabular}

Abbreviation: LOS: length of stay; SD: standard deviation; ${ }^{\dagger} p$ value $<0.001$, significant for trend; ${ }^{\ddagger}$ As per NIS database reporting guidelines values $<10$ are not shown in the table.

Table 5. Tukey B test comparing overall length of stay across different age groups in 118,947 patients undergoing Carotid Endarterectomy (CEA) as a primary procedure between 2004 and 2008.

\begin{tabular}{cccccc}
\hline & & \multicolumn{4}{c}{ Subset for alpha $=0.01$} \\
\cline { 3 - 5 } Age groups & $\mathrm{N}$ & 1 & 2 & 3 & 4 \\
\hline 51 - 60 years & 14270 & 2.45 & & & \\
61 - 70 years & 36067 & 2.39 & & & \\
71 - 80 years & 45663 & 2.62 & & & \\
41 - 50 years & 2420 & & 2.81 & & \\
81 - 90 years & 19910 & & & 3.12 & \\
$>$ 91 years & 617 & & & & 3.94 \\
\hline
\end{tabular}

Abbreviation: N: number of patients. Tukey B post-hoc comparison of the six age groups for length of stay indicates that patients $>91$ years had highest length of stay (Mean $[M]=3.94$ days), followed by patients in the $9^{\text {th }}$ decade $\left(\mathrm{M}=3.12\right.$ days) and $5^{\text {th }}$ decade $(\mathrm{M}=2.81$ days), whereas patients in the $6^{\text {th }}$ to $8^{\text {th }}$ decade had lowest length of stay, $p<0.01$. There was no significant difference in the length of stay between the patients in the $6^{\text {th }}$ to $8^{\text {th }}$ decade.

with advancing age. Five percent of the overall patient population was discharged to nursing home or another short term hospital; however such arrangements were required by $24.4 \%$ of those in the oldest age group ( $>91$ years). The average hospital charges were \$25,969 - \$ 26,876 for the entire group of patients; however a trend towards increased hospital cost with advancing age, or non-elective case status was noted.

\subsection{Procedural Related Complications}

Overall 5.1\% of CEA patients experienced one of 5 procedural related complications, including hematoma (2.5\%), stroke (0.9\%), Myocardial Infarction (MI) (0.8\%), hemorrhage $(0.8 \%)$, and cranial nerve injury $(0.1 \%)$ (Table 6). The highest incidence of stroke, hemorrhage and hematoma occurred in the oldest age group ( $>91$ years), while the highest incidence of MI was among those 61 - 70 years or 81 - 90 years, $p<0.001$. The incidence of cranial nerve injury was very low $(0.1 \%)$ and did not vary substantially across the age spectrum.

\subsection{In-Hospital Mortality}

The overall CEA in-hospital mortality rate for the entire study group was $0.4 \%$. The lowest CEA related mortality of $0.2 \%$ was seen in the youngest patients (41 - 50 years), while the highest mortality of $2.6 \%$ was seen in the old- 
Table 6. Age related procedural complications among 118,947 patients undergoing Carotid Endarterectomy (CEA) as a primary procedure between 2004 and 2008.

\begin{tabular}{cccccccc}
\hline \multirow{2}{*}{ Complications, N (\%) } & \multicolumn{7}{c}{ Patients' age groups by decades } \\
\cline { 2 - 7 } & Overall & $\mathbf{4 1}$ - 50 years & $\mathbf{5 1}$ - 60 years & $\mathbf{6 1}$ - 70 years & $\mathbf{7 1 ~ - ~ 8 0 ~ y e a r s ~}$ & $\mathbf{8 1}$ - 90 years & $\begin{array}{c}>\mathbf{9 1}, \\
\text { years }\end{array}$ \\
\hline Hematoma $^{*}$ & $2990(2.5)$ & $52(2.1)$ & $266(1.9)$ & $754(2.1)$ & $1271(2.8)$ & $630(3.2)$ & $17(2.8)$ \\
Stroke $^{*}$ & $1028(0.9)$ & $27(1.1)$ & $132(0.9)$ & $307(0.9)$ & $360(0.8)$ & $193(1.0)$ & $(1.5)^{\ddagger}$ \\
Myocardial infarction $^{*}$ & $981(0.8)$ & $(0.4)^{\ddagger}$ & $76(0.5)$ & $276(1.1)$ & $388(0.8)$ & $226(1.1)$ & $(0.8)^{\ddagger}$ \\
Hemorrhage & $915(0.8)$ & $(0.4)^{\ddagger}$ & $73(0.5)$ & $255(0.7)$ & $369(0.8)$ & $203(1.0)$ & $(1.0)^{\ddagger}$ \\
Cranial nerve injury & $126(0.1)$ & $(0.04)^{\ddagger}$ & $19(0.1)$ & $33(0.1)$ & $49(0.1)$ & $23(0.1)$ & 0 \\
\hline
\end{tabular}

Abbreviations: N: number of patients; SD: standard deviation; LOS: length of stay; DRG: diagnosis related groups; ${ }^{*} p$ value $<0.001$, significant for trend; ${ }^{\ddagger}$ As per NIS database reporting guidelines, values $<10$ are not shown in the table.

est patients ( $>91$ years). This difference constituted a $450 \%$ increased CEA mortality rate in patients $>90$ years compared to patients in their 5th decade. The combined stroke/mortality rate for the entire study group was $1.2 \%$, and this increased with advancing age peaking at $2.6 \%$ for the oldest age group. This difference constituted a $100 \%$ increased CEA combined stroke/mortality rate in patients $>90$ years compared to patients in their 5th decade.

\subsection{Univariate and Multivariate Analysis}

Univariate analysis looking at all abstracted variables, including age demonstrated that advancing age and nearly all factors analyzed were associated with increased CEA mortality (Table 7). On multivariate analysis to detect independent factors which contributed to an increased in overall mortality, non-elective admission status, age 81 90 years, African American and Hispanic racial groups, Charlson co-morbidity index score between 1 - 5, symptomatic presentation, diabetes, hypertension, congestive heart failure and renal failure, independently affected mortality on multivariate analysis (Table 8). Multivariate analysis of factors affecting mortality for each individual age group was also completed (Table 9). Factors which independently affected mortality were CHF for 5th decade; CHF and DM with chronic complications for 6th decade; female gender, CHF, DM with chronic complications, HTN, liver disease, and Charlson score of 1 to 5 for 7th decade; CHF, DM with or without chronic complications, and Charlson score of 1 to 10 for 8th decade; CHF and HTN for 9th decade; and DM with chronic complications for 10th decade.

\section{Discussion}

The two landmark CEA trials, the North American Symptomatic Carotid Endarterectomy Trail (NASCET) and Asymptomatic Carotid Atherosclerosis Study (ACAS) trials, have clearly established CEA as the gold standard for stroke prevention in patients with both symptomatic
Table 7. Univariate Analysis of In-Hospital Mortality among 118,947 patients undergoing carotid endarterectomy as a primary procedure.

\begin{tabular}{|c|c|c|}
\hline Variable & $\begin{array}{l}\text { Mortality } \\
\text { rate, } \%\end{array}$ & $p$ value ${ }^{*}$ \\
\hline \multicolumn{3}{|l|}{ Overall } \\
\hline Age groups & & 0.001 \\
\hline 41 - 50 years & 0.2 & \\
\hline 51 - 60 years & 0.2 & \\
\hline 61 - 70 years & 0.3 & \\
\hline 71 - 80 years & 0.4 & \\
\hline 81 - 90 years & 0.7 & \\
\hline$>90$ years & 1.1 & \\
\hline Gender & & 0.3 \\
\hline Male & 0.3 & \\
\hline Female & 0.4 & \\
\hline Race & & 0.005 \\
\hline White & 0.3 & \\
\hline Black & 0.7 & \\
\hline Hispanic & 0.6 & \\
\hline Asian or Pacific Islander & 0.6 & \\
\hline Native American & 0.3 & \\
\hline Others & 0.4 & \\
\hline Type of Presentation & & 0.001 \\
\hline Asymptomatic CAS & 0.3 & \\
\hline Symptomatic CAS & 1.6 & \\
\hline Type of admission & & 0.001 \\
\hline Non-elective admission & 0.9 & \\
\hline Elective admission & 0.3 & \\
\hline \multicolumn{3}{|l|}{ Comorbidities } \\
\hline Renal failure & 1.2 & 0 \\
\hline Congestive heart failure & 1.7 & 0 \\
\hline Liver disease & 1.1 & 0.017 \\
\hline Peripheral vascular disorders & 0.4 & 0.861 \\
\hline Diabetes with chronic complications & 0.8 & 0 \\
\hline \multicolumn{3}{|l|}{ Valvular disease } \\
\hline Chronic pulmonary disease & 0.6 & 0 \\
\hline Diabetes, uncomplicated & 0.3 & 0.036 \\
\hline $\begin{array}{l}\text { Hypertension (combine uncomplicated } \\
\text { and complicated) }\end{array}$ & 0.3 & 0 \\
\hline
\end{tabular}

Abbreviations: CAS: carotid artery stenosis; ${ }^{*} p$ value $<0.05$ Statistical significance. 
Table 8. Multivariate analysis of factors affecting mortality among 118,947 patients undergoing Carotid Endarterectomy as a primary procedure between 2004-2008.

\begin{tabular}{ccc}
\hline & Odds Ratio (95 C.I.) & $p$ value $^{*}$ \\
\hline Non-elective & $2.1(1.6-2.6)$ & 0.0001 \\
Age & Reference & \\
41 - 50 years & $1.1(0.4-3.2)$ & 0.85 \\
51 - 60 years & $1.3(0.5-3.6)$ & 0.61 \\
61 - 70 years & $1.6(0.6-4.4)$ & 0.35 \\
71 - 80 years & $2.9(1.1-8.0)$ & 0.04 \\
81 - 90 years & $2.9(0.7-11.7)$ & 0.14 \\
$>91$ years & Reference & \\
Race & $1.7(1.1-2.7)$ & 0.02 \\
White & $1.7(1.1-2.6)$ & 0.02 \\
Black & & \\
Hispanic & Reference & \\
Charlson score & $1.7(1.3-2.4)$ & 0.00 \\
Charlson score, 0 & $1.7(1.1-2.5)$ & 0.01 \\
Charlson score, 1 - 5 & $3.7(2.8-4.8)$ & 0.001 \\
CAS with stroke & $0.6(0.5-0.9)$ & 0.001 \\
CHF & $0.5(0.4-0.6)$ & 0.001 \\
DM & $2.2(1.6-3.1)$ & 0.001 \\
HTN & & \\
Renal failure & & \\
\hline
\end{tabular}

Abbreviations: C.I.: confidence interval; CHF: congestive heart failure; HTN: hypertension; DM: diabetes mellitus; CAS: carotid artery stenosis; *p value $<0.05$ : statistical significance. and asymptomatic carotid artery stenosis [11]. Data from published reports demonstrates a stroke rate of $16 \%$ following conservative management compared to $2 \%$ following CEA in age-matched controls after 8 years of follow-up [12]. Moreover, nearly all contemporary CEA outcome studies have documented further improvement in the peri-operative morbidity and mortality over the last two decades, due in large part to the use of carotid duplex instead of angiography, improved medical therapy, the use of patch angioplasty, improved vascular surgical training, and improved anesthesia protocols [13]. However, despite these results, and widespread consensus on the efficacy of CEA for stroke prevention in specific circumstances, the results of NASCET and ACAS, as well as other reports, including registry data maintained by vascular and stroke societies and population databases, are difficult to generalize to "all patients" [14]. A major limitation of these studies is the highly select nature of patient and provider populations in clinical trials (notably both ACAS and NASCET excluded patients over 80 years of age), and the inherent coding bias and selection bias in population database studies [10,14]. Therefore, at present the true incidence of peri-operative morbidity, namely stroke or MI, as well as mortality following CEA in the elderly (defined as over 80 years old) or "super elderly" (defined as over 90 years old), remains largely unknown or anecdotal. The limited data that currently exists (which is primarily single institutional and retrospective) places the peri-operative combined rates of stroke and mortality in these patients between $1.3 \%-21.1 \%$ and the peri-ope-

Table 9. Significant factors affecting mortality on Multivariate analysis among 118,947 patients undergoing Carotid Endarterectomy as a primary procedure separated by patients’ age groups (2004-2008).

\begin{tabular}{|c|c|c|c|c|c|c|c|c|c|c|c|c|}
\hline \multirow{3}{*}{ Variables } & \multicolumn{12}{|c|}{ Patients' Age Groups by Decades } \\
\hline & \multicolumn{2}{|c|}{41 - 50 years } & \multicolumn{2}{|c|}{51 - 60 years } & \multicolumn{2}{|c|}{61 - 70 years } & \multicolumn{2}{|c|}{71 - 80 years } & \multicolumn{2}{|c|}{81 - 90 years } & \multicolumn{2}{|c|}{$>91$ years } \\
\hline & $\begin{array}{c}\text { OR } \\
\text { (95\% C.I.) } \\
\end{array}$ & $p$ value ${ }^{*}$ & $\begin{array}{c}\text { OR } \\
(95 \% \text { C.I. })\end{array}$ & $p$ value $^{*}$ & $\begin{array}{c}\text { OR } \\
(95 \% \text { C.I. }) \\
\end{array}$ & $p$ value ${ }^{*}$ & $\begin{array}{c}\text { OR } \\
(95 \% \text { C.I. })\end{array}$ & $p$ value $^{*}$ & $\begin{array}{c}\text { OR } \\
(95 \% \text { C.I. }) \\
\end{array}$ & $p$ value ${ }^{*}$ & $\begin{array}{c}\text { OR } \\
(95 \% \text { C.I. }) \\
\end{array}$ & $p$ value $^{*}$ \\
\hline Female gender & & & & & $\begin{array}{c}0.6 \\
(0.3-1.0)\end{array}$ & 0.056 & & & & & & \\
\hline CHF & $\begin{array}{c}9.7 \\
(1.0-94.4)\end{array}$ & 0.05 & $\begin{array}{c}3.4 \\
(1.1-10.5)\end{array}$ & 0.03 & $\begin{array}{c}3.2 \\
(1.7-6.1)\end{array}$ & 0.001 & $\begin{array}{c}3.9 \\
(2.5-6.2)\end{array}$ & 0.001 & $\begin{array}{c}4.3 \\
(2.8-6.6)\end{array}$ & 0.001 & & \\
\hline $\mathrm{DM}$ & & & & & & & $\begin{array}{c}0.4 \\
(0.3-0.7)\end{array}$ & 0.001 & & & & \\
\hline $\begin{array}{c}\text { DM with } \\
\text { Complications }\end{array}$ & & & $\begin{array}{c}4.0 \\
(1.3-12.4)\end{array}$ & 0.02 & $\begin{array}{c}2.3 \\
(1.0-5.3)\end{array}$ & 0.057 & $\begin{array}{c}0.4 \\
(0.4-0.6)\end{array}$ & 0.001 & & & $\begin{array}{c}181.5 \\
(8.2-4031.7)\end{array}$ & 0.001 \\
\hline Hypertension & & & & & $\begin{array}{c}0.4 \\
(0.2-0.7)\end{array}$ & 0.002 & & & $\begin{array}{c}0.6 \\
(0.4-0.9)\end{array}$ & 0.021 & & \\
\hline Liver disease & & & & & $\begin{array}{c}4.8 \\
(1.1-21.2)\end{array}$ & 0.036 & & & & & & \\
\hline Charlson score 1 - 5 & & & & & $\begin{array}{c}2.4 \\
(1.1-5.1)\end{array}$ & 0.022 & $\begin{array}{c}2.0 \\
(1.2-3.3)\end{array}$ & 0.007 & & & & \\
\hline Charlson score $>5$ & & & & & & & $\begin{array}{c}4.7 \\
(1.0-22.0)\end{array}$ & 0.049 & & & & \\
\hline
\end{tabular}

Abbreviations: OR: odds ratio; C.I.: confidence interval; CHF: congestive heart failure; DM: diabetes mellitus; ${ }^{*} p$ value $<0.05$ : statistical significance. 
rative stroke rate between $1.0 \%$ and $14.5 \%$ [11,15-19]. If the higher end of this range is accurate, then CEA in the older patient would clearly be unjustified since it is generally accepted that the combined stroke and death rate from CEA for symptomatic patients should be less than $5 \%$, and for asymptomatic patients, less than 3\% [20].

Fischer, et al. reviewed Medicare claim files involving 2089 New England residents over 65 years who underwent CEA between 1984 and 1985, and reported a mortality of $4.7 \%$ for those older than 80 years compared to $1.1 \%$ for patients aged 65 to 69 years [6]. A 3-fold higher risk of death ensued if the procedure was performed at a hospital that performed less than 40 CEA/year. A similar direct correlation between age and operative mortality was also demonstrated in several more recent studies, and in at least one study, CEAs performed in patients over 75 years was associated with improved quality of life, but not survival advantage $[9,21]$. In a separate review of 11,973 CEAs performed over a 6-year period, Maxwell, et al. reported substantially higher mortality rates in patients older than 75 years (2.1\%) compared to those $<75$ years $(0.9 \%)$ [22]. A notable limitation of most of the aforementioned studies to answer the question, "Is CEA justified in the elderly or super elderly" is the fact that in most instances outcomes in older patients were analyzed solely by age and without consideration as to whether the patient had significant co-morbidities, had surgery electively or non-electively, or had prior neurological events among other variables. It goes without saying that if the institutional or surgical bias is towards exclusion of certain patients deemed a "high risk" for CEA (e.g., end-stage renal disease, or congestive heart failure patients), the results attained would likely be more favorable than if the "high risk" group were included. The current study represents that largest effort to attempt to identify whether age alone, or age in combination with specific pre-existing co-morbidities, or other factors are independent predictors of surgical outcomes and mortality following CEA.

Several "high risk" factors for mortality following CEA have been identified, including age $>80$ years, active cardiac disease, chronic pulmonary disease [23], symptomatic carotid stenosis [24], intra-operative transfusion, prior major stroke, shorter height, and increased anesthesia time [23]. In the current study we sought critically to assess, through both univariate and multivariate analysis, which factors were most predictive of CEA related mortality. In the current study, advancing age and nearly all other factors analyzed (Table 7) appeared to impact CEA mortality rates on univariate analysis. Multivariate analysis revealed that age by itself is only a weak independent predictor of CEA mortality, and only in those between 81 to 90 years. Much stronger CEA mortality independent associations were seen if the pa- tient were African-American or Hispanic, had a Charlson co-morbidity index score of 1 to 5, exhibited a symptomatic presentation, or suffered from congestive heart failure or renal failure. In further subgroup analysis addressing the impact of these different factors across various age groups, only congestive heart failure demonstrated an age-independent negative effect on CEA mortality rates. Diabetes without systemic complications was a risk factor for mortality among those 71 to 80 years, while diabetes with systemic complications was significant for those 51 to 80 years, as well as those $>90$ years. Similarly, hypertension was significant for 7th decade and 9th decade, liver disease for 7th decade, and a Charlson co-morbidity index score of 1 to 5 for those 61 to 80 years. Interestingly, female patients, in whom a higher incidence of adverse events after CEA has been reported, actually demonstrated no difference or improved mortality rates in specific age groups on multivariate analysis (61 to 70 years, Odds Ratio, 0.6; 95\% Confidence Interval, $0.3-1.0, p=0.056)[25,26]$.

Several secondary non-clinical outcome measures have also been extensively studied in patients undergoing CEA, pertinent to them are length of stay, cost of care and discharge disposition of patients following CEA. Many recent studies have reported substantial decreases in CEA length of stays since the implementation of postoperative critical pathways [27]. Although elderly patients still have a higher LOS, several authors have noted that the once published large difference in LOS between elderly and younger patients has narrowed (2.1 to 5.6 days for elderly vs. 1.6 to 4.5 days for young patients) $[8,28,29]$. Salameh, et al. observed a mean LOS of $1.2 \pm 0.7$ days for patients $>81$ years compared to $1.5 \pm 0.6$ days for patients in the 7th decade after adjusting for complication rates, $p=$ N.S. [9]. In the current study, we found a significant difference in the LOS of stay following CEA across different age groups. Using the Tukey B post-hoc test to assess the significance of LOS differences across age groups, we noted a significant difference in the LOS for the 5th decade compared to all other age groups, the 6th through 8th decade compared to all others, and a prolonged LOS for 9th and 10th decade compared to all others, $p<0.001$. The highest LOS was noted in patients $>90$ years ( $3.9 \pm 4.2$ days), but the reasons for increased LOS in the 5 th decade were not clear ( $2.8 \pm 3.9$ days), but may be related to increased acuity reflected in a higher incidence of non-elective cases (27\%). Recently, several studies have analyzed the cost-effectiveness of CEA treatment $[27,30]$. Dorafshar, et al. compared the cost of CEA care for patients $>85$ years $(\mathrm{N}=30)$ to those < 85 years $(\mathrm{N}=95)$. These authors noted a significant increase in both direct and indirect costs for CEA in the oldest population group [27]. In the current study we also noted that the total hospital charges increased with age, 
with a $12.1 \%$ increase in hospital charges for patients $>91$ years compared to patients in 5th decade of life. Interestingly, the hospital charges were less for the 6th decade $(-7.5 \%)$ and 7 th decade $(-0.5 \%)$ when compared to 5 th decade of life, perhaps once again reflecting a higher cost of care and LOS for non-elective cases. However, a more complete explanation is not possible with the current study design. In an effort to reduce the cost of acute-care hospitalization, early transfer to nursing homes or rehabilitation centers following surgical treatment has now become the norm, especially among the elderly population [31]. The result of this trend has been to shift costs from acute-care hospitals to long-term care facilities; however, whether this trend applies to CEA patients was previously unknown. In the current study, we identified that overall $10 \%$ of CEA patients required on-going medical care after being discharged from the acute-care facility, and this number increased to $30 \%$ in patients $>90$ years of age. The precise explanation for the need for continued medical care after discharge in the elderly and super elderly is unknown but is likely related to increasing co-morbidities and complication rates in this population.

The limitations of our study include those inherent to large administrative databases, such as errors in coding and sampling, and the inability to determine the percentage of carotid stenosis [32]. Immediate post-operative complications were apparent in NIS database; however, re-admissions for a complication within 30 days of CEA were not identifiable, likely resulting in an underestimation of the actual complication rates. Of note however, this limitation would apply to all age groups, and should not have altered the overall findings of this report. Another potential limitation of this study design is under adjustment for co-morbidities in elderly patients. In an effort to avoid this limitation, we used the Charlson Comorbidity Index, which consists of nine categories of comorbid conditions for better assessment of patient's preoperative function. Further, there is no information regarding the degree of carotid stenosis, the side of disease, presence of contralateral occlusion, diagnostic methods and arteriographic findings, timing of surgery relative to qualifying event, technical details on the procedure (such as type of closure and protection devices), surgeon characteristics (including specialty and volume) and lack of objective observer analysis, for determination of stroke after the procedure. The postoperative strokes are not divided into disabling or nondisabling and there is no categorization of postoperative stroke using RANKIN scores.

In summary, we can conclude that the overall mortality rate following CEA is low (0.4\%), even in the super elderly ( $>90$ years, $1.1 \%$ ). Perhaps most importantly, is it clear that while advanced age is an independent predictor of increased morbidity and mortality following CEA, this increase occurs by no means in a linear fashion. Indeed, age alone predicted increased CEA mortality only for that age 81 to 90 years. More important than chronologic age, was "physiologic age" reflected in the number or specific co-morbidities in which a patient of any age was afflicted. CHF, DM, HTN and renal failure were all independent predictors of increased CEA mortality for the group as a whole, as well as for unique age groups; however, only CHF was uniformly associated with increased CEA mortality in all age groups. The number of co-morbidities as reflected in the Charlson co-morbidity index score similarly demonstrates that it is "sick" old patients, rather than just old patients who are most at risk of increased mortality following CEA. African-American or Hispanic racial/ethnic groups also appear to have increased CEArelated mortality compared to Caucasians, but analysis is limited by small numbers in different groups, even in this large database. As the percent of patients over 80 years continue to grow rapidly, and in light of a predicted life expectancy of eight years for this group, data such as that provided by this study should permit more judicious decision-making by surgeons, institutions and insurers, as the ever increasing demand for more healthcare and more expensive technology shows no sign of diminishing. Can CEA be performed safely in elderly and super elderly patients with low and acceptable risks of stroke and death? The answer is a resounding yes! Should CEA be performed in the elderly and super elderly and in whom, remains the unanswered question. This study sheds only some initial light on the answer to this question, but fails to address the issue of just because we can, doesn't mean we should. Many clinician follow the dictum that "every patient is a series of one" when they negate findings in large studies as non-applicable to their individual patients. However, unless we seek data such as that provided here to help better inform us as to how to make tough decisions about rationing healthcare, we will sizzle ourselves to insolvency in our quest for new technology and all things for all people.

\section{REFERENCES}

[1] Research Activities, AHRQ, US Department of Health and Human Services, 2012. http://archive.ahrq.gov/research/sep03/0903RA.pdf

[2] B. Cartier, "Carotid Surgery in Octogenarians: Why Not," Annals of Vascular Surgery, Vol. 16, No. 6, 2002, pp. 751755. doi:10.1007/s10016-001-0243-0

[3] P. A. Wolf, R. B. D’Agostino, A. J. Belanger and W. B. Kannel, "Probability of Stroke: A Risk Profile from the Framingham Study,” Stroke, Vol. 22, 1991, pp. 312-318. doi:10.1161/01.STR.22.3.312

[4] United States Census Bureau, 2012. http://www.census.gov/population/www/projections/natd et-d1a.html 
[5] R. J. McKenna, "Clinical Aspects of Cancer in the Elderly. Treatment Decisions, Treatment Choices, and Follow-Up," Cancer, Vol. 74, No. 7, 1994, pp. 2107-2117. doi:10.1002/1097-0142(19941001)74:7+<2107::AID-CN CR2820741719>3.0.CO;2-1

[6] E. S. Fisher, D. J. Malenka, N. A. Solomon, T. A. Bubolz, F. S. Whaley and J. E. Wennberg, "Risk of Carotid Endarterectomy in the Elderly," American Journal of Public Health, Vol. 79, No. 12, 1989, pp. 1617-1620. doi:10.2105/AJPH.79.12.1617

[7] M. T. Miller, A. J. Comerota, A. Tzilinis, Y. Daoud and J. Hammerling, "Carotid Endarterectomy in Octogenarians: Does Increased Age Indicate 'High Risk', Journal of Vascular Surgery, Vol. 41, No. 2, 2005, pp. 231-237. doi:10.1016/j.jvs.2004.11.021

[8] B. A. Perler, A. Dardik, G. P. Burleyson, T. A. Gordon and G. M. Williams, "Influence of Age and Hospital Volume on the Results of Carotid Endarterectomy: A StateWide Analysis of 9918 Cases," Journal of Vascular Surgery, Vol. 27, No. 1, 1998, pp. 25-31. doi:10.1016/S0741-5214(98)70288-5

[9] J. R. Salameh, J. L. Myers and D. Mukherjee, "Carotid Endarterectomy in Elderly Patients: Low Complication Rate with Overnight Stay,” Archives of Surgery, Vol. 137, No. 11, 2002, pp. 1284-1287. doi:10.1001/archsurg.137.11.1284

[10] T. R. Vogel, V. Y. Dombrovskiy, P. B. Haser, J. C. Scheirer, and A. M. Graham, "Outcomes of Carotid Artery Stenting and Endarterectomy in the United States,” Journal of Vascular Surgery, Vol. 49, No. 2, 2009, pp. 325-330. doi:10.1016/j.jvs.2008.08.112

[11] H. J. Barnett, D. W. Taylor, M. Eliasziw, A. J. Fox, G. G. Ferguson, R. B. Haynes, R. N. Rankin, G. P. Clagett, V. C. Hachinski, D. L. Sackett, K. E. Thorpe, H. E. Meldrum and J. D. Spence, "Benefit of Carotid Endarterectomy in Patients with Symptomatic Moderate or Severe Stenosis. North American Symptomatic Carotid Endarterectomy Trial Collaborators," The New England Journal of Medicine, Vol. 339, No. 20, 1998, pp. 1415-1425. doi:10.1056/NEJM199811123392002

[12] D. Rosenthal, R. H. Rudderman, D. H. Jones, M. D. Clark, P. E. Stanton, P. A. Lamis Jr. and W. W. Daniels, "Carotid Endarterectomy in the Octogenarian: Is It Appropriate,” Journal of Vascular Surgery, Vol. 3, No. 5, 1986, pp. 782-787.

[13] T. F. Kresowik, D. Bratzler, H. R. Karp, R. A. Hemann, M. E. Hendel, S. L. Grund, M. Brenton, E. F. Ellerbeck and D. S. Nilasena, "Multistate Utilization, Processes, and Outcomes of Carotid Endarterectomy," Journal of Vascular Surgery, Vol. 33, No. 2, 2001, pp. 227-234. doi:10.1067/mva.2001.111881

[14] J. Garg, D. A. Frankel and R. B. Dilley, "Carotid Endarterectomy in Academic versus Community Hospitals: The National Surgical Quality Improvement Program Data," Annals of Vascular Surgery, Vol. 25, No. 4, 2011, pp. 433-441. doi:10.1016/j.avsg.2010.12.008

[15] T. Brott and K. Thalinger, "The Practice of Carotid Endarterectomy in a Large Metropolitan Area,” Stroke, Vol. 15, No. 6, 1984, pp. 950-955. doi:10.1161/01.STR.15.6.950
[16] J. D. Easton and D. G. Sherman, “Stroke and Mortality Rate in Carotid Endarterectomy: 228 Consecutive Operations,” Stroke, Vol. 8, No. 5, 1977, pp. 565-568. doi:10.1161/01.STR.8.5.565

[17] D. S. Kucey, B. Bowyer, K. Iron, P. Austin, G. Anderson and J. V. Tu, "Determinants of Outcome after Carotid Endarterectomy,” Journal of Vascular Surgery, Vol. 28, No. 6, 1998, pp. 1051-1058. doi:10.1016/S0741-5214(98)70031-X

[18] J. R. Perry and J. W. Norris, "Asymptomatic Carotid Artery Stenosis,” Archives of Neurology, Vol. 54, No. 7, 1997, pp. 799-800. doi:10.1001/archneur.1997.00550190005002

[19] J. D. Richardson and K. A. Main, "Carotid Endarterectomy in the Elderly Population: A Statewide Experience," Journal of Vascular Surgery, Vol. 9, No. 1, 1989, pp. 6573.

[20] J. Biller, W. M. Feinberg, J. E. Castaldo, A. D. Whittemore, R. E. Harbaugh, R. J. Dempsey, L. R. Caplan, T. F. Kresowik, D. B. Matchar, J. F. Toole, J. D. Easton, H. P. Adams, L. M. Brass, R. W. Hobson, T. G. Brott and L. Sternau, "Guidelines for Carotid Endarterectomy: A Statement for Healthcare Professionals from a Special Writing Group of the Stroke Council, American Heart Association,” Circulation, Vol. 97, No. 5, 1998, pp. 501-509. doi:10.1161/01.CIR.97.5.501

[21] D. C. Hsia, L. M. Moscoe and W. M. Krushat, "Epidemiology of Carotid Endarterectomy among Medicare Beneficiaries,” Stroke, Vol. 29, No. 2, 1998, pp. 346-350. doi:10.1161/01.STR.29.2.346

[22] J. G. Maxwell, E. J. Rutherford, D. L. Covington, P. Churchill, R. D. Patrick, C. Scott and T. V. Clancy, "Community Hospital Carotid Endarterectomy in Patients over Age 75," The American Journal of Surgery, Vol. 160, No. 6, 1990, pp. 598-603. doi:10.1016/S0002-9610(05)80753-6

[23] J. L. Kang, T. K. Chung, R. T. Lancaster, G. M. Lamuraglia, M. F. Conrad and R. P. Cambria, "Outcomes after Carotid Endarterectomy: Is There a High-Risk population? A National Surgical Quality Improvement Program Report,” Journal of Vascular Surgery, Vol. 49, No. 2, 2009, pp. 331-339.

[24] J. Golledge, R. Cuming, D. K. Beattie, A. H. Davies and R. M. Greenhalgh, "Influence of Patient-Related Variables on the Outcome of Carotid Endarterectomy," Journal of Vascular Surgery, Vol. 24, No. 1, 1996, pp. 120-126. doi:10.1016/S0741-5214(96)70152-0

[25] M. K. Kapral, H. Wang, P. C. Austin, J. Fang, D. Kucey, B. Bowyer and J. V. Tu, "Sex Differences in Carotid Endarterectomy Outcomes: Results from the Ontario Carotid Endarterectomy Registry,” Stroke, Vol. 34, No. 5, 2003, pp. 1120-1125. doi:10.1161/01.STR.0000066681.79339.E2

[26] M. A. Mattos, D. S. Sumner, W. T. Bohannon, J. Parra, R. B. McLafferty, L. A. Karch, D. E. Ramsey and K. J. Hodgson, "Carotid Endarterectomy in Women: Challenging the Results from ACAS and NASCET,” Annals of Surgery, Vol. 234, No. 4, 2001, pp. 438-445. doi:10.1097/00000658-200110000-00003

[27] A. H. Dorafshar, T. D. Reil, W. S. Moore, W. J. Quinones- 
Baldrich, N. Angle, F. Fahoomand, S. S. Ahn, H. A. Gelabert, J. D. Baker and J. A. Freischlag, "Cost Analysis of Carotid Endarterectomy: Is Age a Factor?” Annals of Vascular Surgery, Vol. 18, No. 6, 2004, pp. 729-735. doi:10.1007/s10016-004-0107-5

[28] A. Kazmers, A. J. Perkins, T. S. Huber and L. A. Jacobs, "Carotid Surgery in Octogenarians in Veterans Affairs Medical Centers,” Journal of Surgical Research, Vol. 81, No. 1, 1999, pp. 87-90. doi:10.1006/jsre.1998.5459

[29] S. P. Roddy, J. M. Estes, M. O. Kwoun, T. F. O’donnell and W. C. Mackey, "Factors Predicting Prolonged Length of Stay after Carotid Endarterectomy,” Journal of Vascular Surgery, Vol. 32, 2000, pp. 550-554. doi:10.1067/mva.2000.107759

[30] J. L. Cronenwett, J. D. Birkmeyer, G. B. Nackman, M. F.
Fillinger, F. R. Bech, R. M. Zwolak and D. B. Walsh, "CostEffectiveness of Carotid Endarterectomy in Asymptomatic Patients. Journal of Vascular Surgery, Vol. 25, No. 2, 1997, pp. 298-309. doi:10.1016/S0741-5214(97)70351-3

[31] P. Haentjens, P. Autier, M. Barette and S. Boonen, “The Economic Cost of Hip Fractures among Elderly Women. A One-Year, Prospective, Observational Cohort Study with Matched-Pair Analysis. Belgian Hip Fracture Study Group,” The Journal of Bone \& Joint Surgery, Vol. 83A, No. 4, 2001, pp. 493-500.

[32] P. S. Romano, "Can Administrative Data Be Used to Compare the Quality of Health Care,” Medical Care Research and Review, Vol. 50, No. 4, 1993, pp. 451-477. doi:10.1177/002570879305000404 